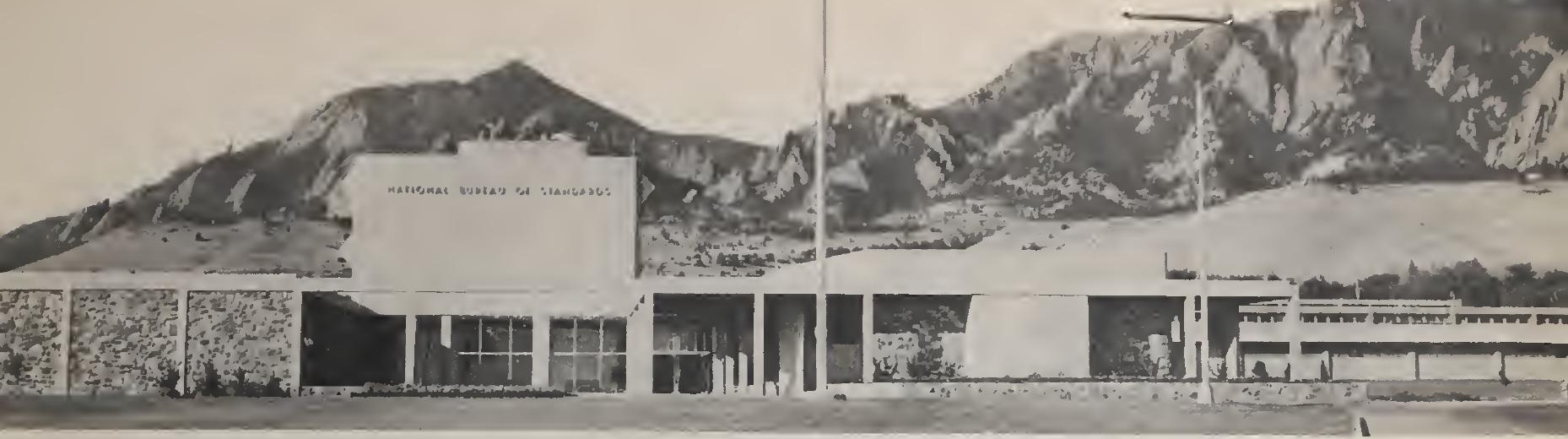

NBS TRANSLATION

6027

PROPERTY OF

SOUTHWEST RE EARCH IIISIITUTE LIBRARY

SAN ANIONIO, TEXAS

CONCERNING A MICROWAVE REFRACTOMETER

(Communication from the Heinrich Hertz Institute of the German Academy of Science at Berlin; Berlin-Adlershof)

\title{
by
}

R. Schunemann and W. Steffen

\section{Translation by}

Albrecht P. Barsis and Moody C. Thompson, Jr.

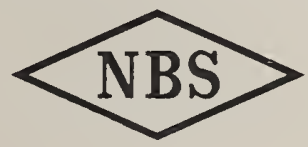

\section{U. S. DEPARTMENT OF COMMER CE NATIONAL BUREAU OF STANDARDS BOULDER LABORATORIES \\ Boulder, Colorado}




\section{THE NATIONAL BUREAU OF STANDARDS}

\section{Functions and Activities}

The functions of the National Burcau of Standards are set forth in the Act of Congress, March 3, 1901, as amended by Congress in Public Law 619, 1950. These include the development and maintenance of the national standards of measurement and the provision of means and methods for making measurements consistent with these standards: the determination of physical constants and properties of materials; the development of methods and instruments for testing materials, devices, and structures; arlvisory scrvices to Govermment Agencies on scientific: and technical problems; invention and development of devices to serve special needs of the Government; and the development of standard practices, codes and specilications. The work inclucles basic and applied rescarch, development, engineering, instrumentation, testing, evaluation, calibration services, and various consultation and information services. A major portion of the Bureau's work is performed for other Govermment Agencies, particularly the Department of Delense and the Atomic Energy Commission. The scope of activities is suggested by the listing of divisions and sections on the inside back cover.

\section{Reports and Publications}

Ihe results of the Bureau's work take the form of either actual equipment and devices or published papers and reports. Reports are issued to the sponsoring agency of a particular project or program. Published papers appear either in the Bureau's own series of publications or in the journals of prolessional and scientific societies. The Bureau itsclf publishes three monthly periodicals, available from the Government Printing Office: The Journal of Research, which presents complete papers reporting technical investigations; the Technical New's Bulletin, which presents summary and preliminary reports on work in progress; and Basic Raclio Propagation Predictions, which provides data for determining the best frequencies to use for radio communications throughout the world. There are also five series of nonperiodical publications: The Applied Mathenratics Series, Circulars, Handbooks, Building Materials and Structures Reports, and Miscellaneous Publications. 
NATIONAL BUREAU OF STANDARDS TRANSLATION NBS PROJECT

NBS TRANSLATION

$8300-11-8305$

November 26, 1958

6027

CONCERNING A MICROWAVE REFRACTOMETER

(Communication from the Heinrich Hertz Institute of the

German Academy of Science at Berlin; Berlin-Adlershof)

\section{by}

R. Schunemann and W. Steffen

Translation by

Albrecht P. Barsis and Moody C. Thompson, Jr.

\section{NBS}

U. S. DEPARTMENT OF COMMERCE

NATIONAL BUREAU OF STANDARDS

BOULDER LABORATORIES

Boulder, Colorado 
IMPORTANT NOTICE

NATIONAL BUREAU OF STAP Approved for public release by the ments intended for use within Director of the National Institute of tion, or open-literoture listing Standards and Technology (NIST) on mission is obtained in writing $f$ 25, D. C. Such permission is $r$ October 9, 2015.

been specificolly prepored if th rogress occounting docuis formolly published it ion, reprinting, reproducot outhorized unless perif Stondords, Woshington for which the Report hos for its own use. 
TABLE OF CONTENTS

Page

Principles of the Refractometer Contruction...... 2

The Cavity Resonator................. 4

Control Devices.................... 6

Calibration....................... 7

Stabilization and Stability of the Device........ 8

Measurement Errors Originating With Air Passage . 9

Construction of the Device............... 10

Initial Test Result .................10

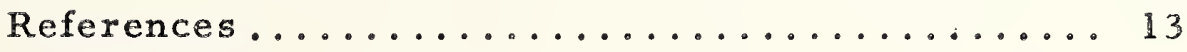



CONCERNING A MICROWAVE REFRACTOMETER

(Communication from the Heinrich Hertz Institute of the German Academy of Science at Berlin; Berlin-Adlershof)

$$
\text { by }
$$

R. Schunemann and W. Steffen

(Translation by Albrecht P. Barsis and Moody C. Thompson, Jr.)

Radio waves within the ultra-shortwave range are scattered in the atmosphere just like light waves. There is, however, a substantial difference between the scattering of light and the scattering of these radio waves. In the case of light, the scattering particles are small as compared to the wave length (molecular structure of the air), whereas in the case of radio waves, they are of the same order of magnitude, or larger (fine structure of the atmosphere). Thus the scattering in this case is highly directional (forward scattering). Processes of this kind which are caused by tropospheric inhomogeneities are the cause for the observed field strength values at ultra-short waves within distances ranging from approximately 100 to 600 kilometers. Here the field strength values caused by diffraction over the earth and refraction in the atmosphere drop below any measurable amount. Knowledge of the origin and the properties of tropospheric inhomogeneities can be obtained only by measurements using very sensitive instruments. The precision of the known temperature and humidity measuring devices is not sufficient for investigations of this kind, especially because of their inertia.

It is known that turbulent eddies are caused by varying incident radiation from the sun, by the shape of the earth's surface, by soil properties, and by stratification of air currents having different temperatures and velocities. One also knows that these eddies 
constantly subdivide until that size is reached where a change to heat is produced by molecular viscosity. Therefore, it may be assumed that eddies of such a dimension which favors scattering processes of ultra-shortwaves are constantly present. However, only the development of microwave refractometers made it possible to measure the intensity as well as the spatial and temporal distribution of such eddies. These refractometers also permitted investigations of the refractive index fluctuations with the necessary degree of accuracy. $\angle 1-5$

The refractive index of the air is only slightly different from unity. Its value depends principally on the type of molecules, their concentration, and their temperature. It is approximately given by

$$
\mathrm{n}=1+\left[\frac{77.5}{\mathrm{~T}}+\left(\frac{\mathrm{P}+4860 \mathrm{e}}{\mathrm{T}}\right)\right] \times 10^{-6}
$$

where $P$ is the atmospheric pressure in millibars, $e$ is the vapor pressure in millibars, and $T$ is the temperature in degrees Kelvin.

Generally, $\mathrm{n}$ varies between 1.000000 and 1.000400. If (n - 1) $\times 10^{6}$ is designated as $N$, the complete recording of a refractive index profile covers a maximum of $400 \mathrm{~N}$-units. But the instrument also has to produce a measureable deflection for variations as small as 0.1 N-unit.

Principles of the Refractometer Construction

The refractometer utilizes as an indicator the dependence of the resonant frequency of a cavity resonator on the dielectric constant of the medium within. If this dielectric constant is varied--e.g. by an increase in temperature- - the frequency change caused thereby is proportional to the variation.

In the method described here a frequency-modulated signal from an oscillator is supplied simultaneously to two cavities. These are acting as circuit elements and do not influence the oscillator frequency 
as such. If the dielectric constants of the media within the resonators, and with them the resonant frequencies differ, the oscillator resonant peaks will appear at different times. This time difference is a direct measure of the difference in the refractive indices. If one cavity is open to the air (measuring cavity), variations of the refractive index may be recorded if the other cavity (reference cavity) is evacuated and sealed. The variations of interest here- $-\Delta \mathrm{n}$ of about $10^{-6}$ or $10^{-7}$ as compared to the mean value- - produce only small differences of the resonant frequencies, and the time difference to be measured is very small. Its determination requires high-Q circuits. This requirement and reasonable dimensions of the cavities necessitate the use of the centimeter-wave region. With $3.2(\mathrm{~cm})$ wavelength a value of $Q$ of about 15, 000 was obtained; this is sufficient for the required accuracy of the measurements.

The device built by us utilizes a type $723 \mathrm{~A} / \mathrm{B}$ klystron as an oscillator. This is frequency-modulated by a saw-tooth repeller voltage; the amount of frequency shift (and thus the sensitivity of the device) may be varied by a stepped voltage divider which permits repetition of settings. The modulated output is coupled to a rectangular wave guide, and is distributed to the two cavity resonators by a branching-T. Attenuator elements prevent reactions between the various circuits and effects on the oscillator.

Fig. 1 shows the basic circuit.

The branching-T network (Fig. 2) has a discontinuity at the branching point even if the branches are terminated and free of reflections unless special precautions are taken. The resistances of the branches are in series so that the main branch is terminated by twice the resistance value. Such a mismatch is avoided by a tuning screw ahead of the branching point. According to its penetration the 
tuning screw acts inductively or capacitively and is adjusted for minimum reflection in the main branch. This is measured by a directional coupler ahead of the branching point. The deviation of the electrical field lines at the branching point is improved by a wedge-shaped step (threshold).

When the klystron frequency is swept, pulses appear in the output of both resonators. These are amplified after having been detected by type OA516 silicon detectors, and produce spikes in blocking oscillator current. Any first spike actuates a multivibrator with the second spike blocking it. Thereby the multivibrator output produces a new pulse, the width of which constitutes a measure of the frequency shift of the measuring cavity compared to the reference cavity. This pulse is finally rectified by a diode; for a fixed reference level the resulting direct current is proportional to the pulse width, and may be utilized for recording.

In order to minimize A.C. hum, the input tube of the audio frequency amplifier has a D.C. filament supply, as its cathode would otherwise be an appreciable source of hum. Current flow via the wave guides between the klystron and the detector mount is prevented by insulated wave guide connectors.

Fig. 3 shows the schematic diagram of the phase meter. The Cavity Resonator

The $Q$ of a cavity resonator depends on the choice of the mode of oscillations, the condition of the surface, and on the ratio of diameter to length. In order to obtain high values, undesired modes must be suppressed and coupling has to be loose. For the device described here the coupling holes have a diameter of 4 millimeters, and the wall. thickness is 0.5 millimeters. The walls are silver-plated and highly polished. Indentations behind the end plates which are connected with 


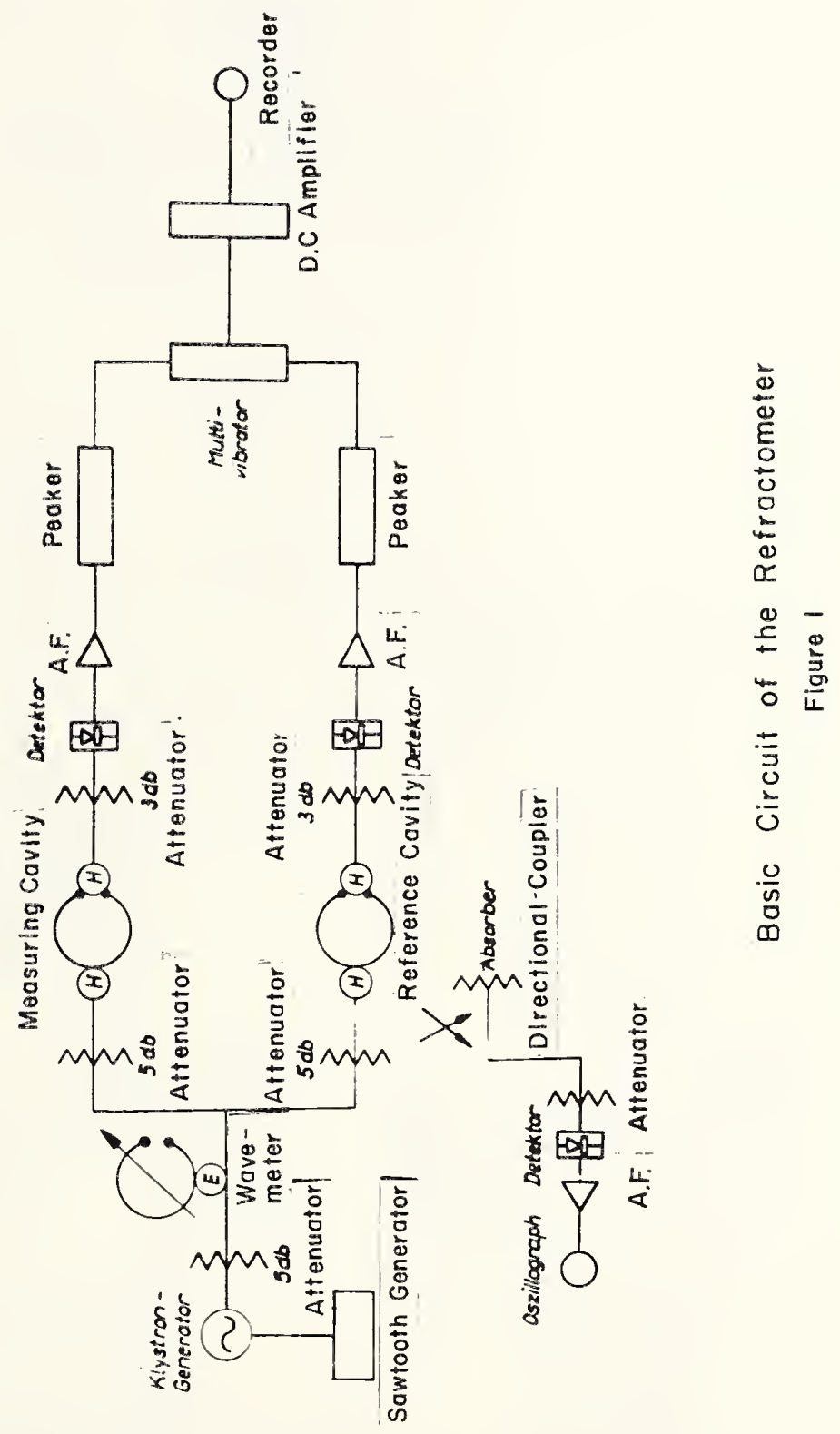





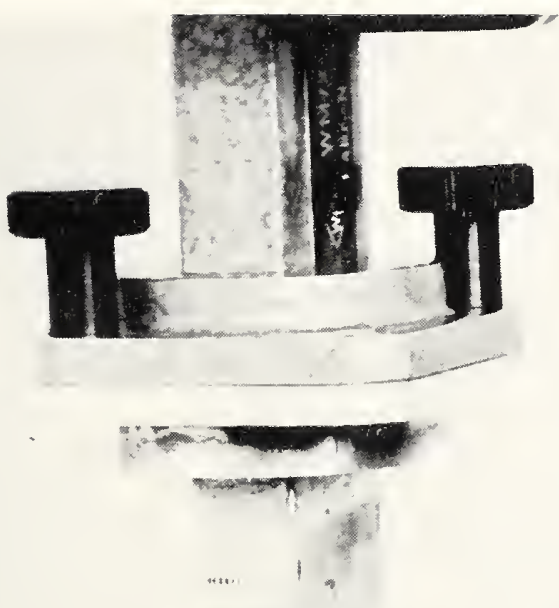

cida

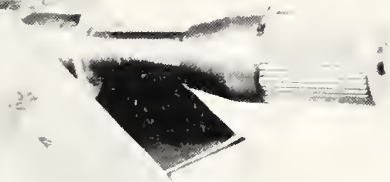

Branch- T

Figure 2

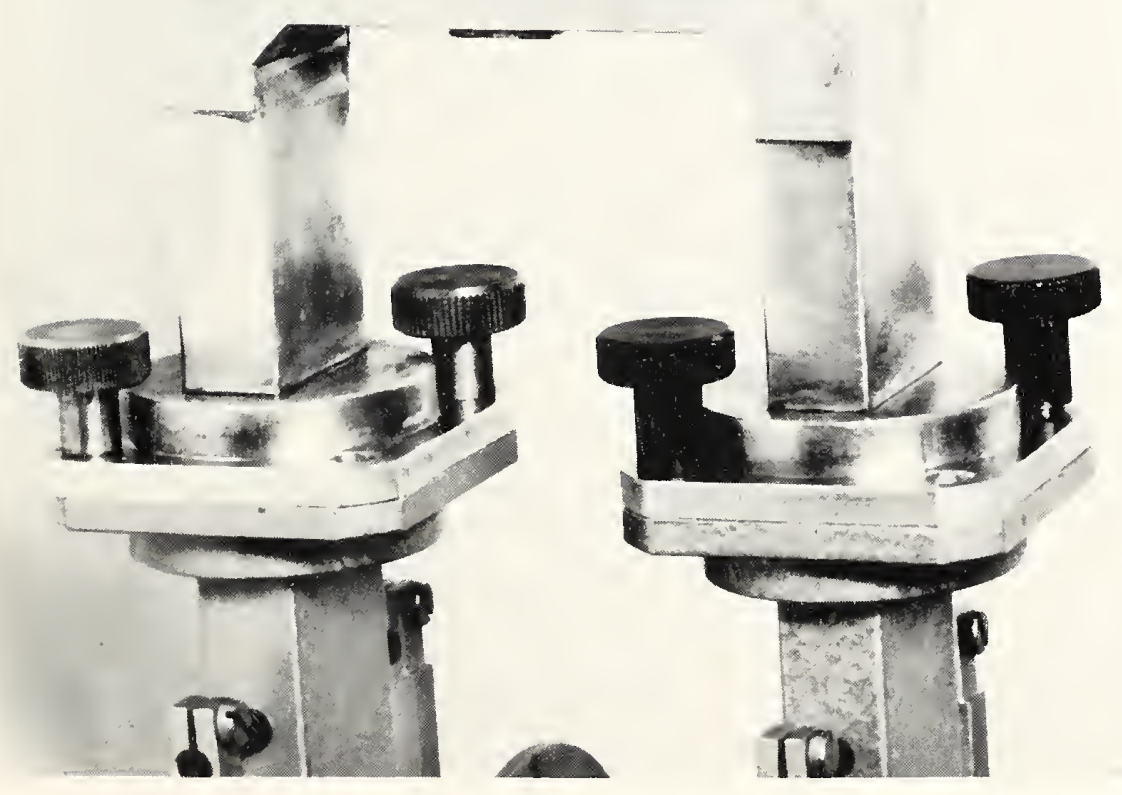





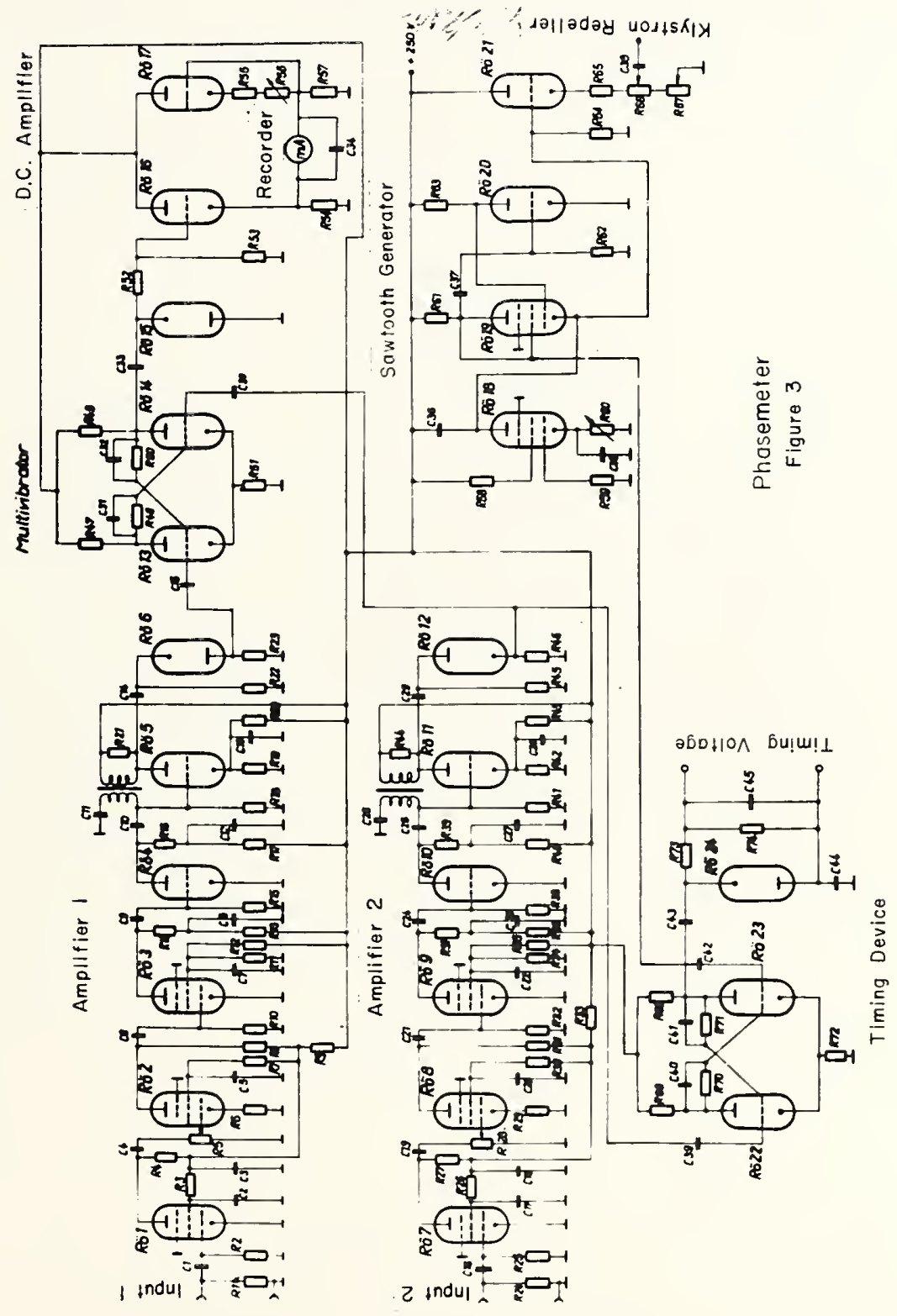



the active portion of the cavity by small slots (see Fig. 8) cause undesired oscillation modes to be shifted in frequency such that the desired mode is not affected.

The type $\mathrm{H}_{011}$-wave is utilized. For this mode maximum $Q$ for the cavity is gained by unity ratio of diameter d and length $\ell$.

The limiting wave length $\lambda_{k}$ and the wave guide wave length $\lambda_{\mathrm{H}}$ are calculated from:

$$
\lambda_{\mathrm{k}}=0.82 \mathrm{~d}
$$

and

$$
\lambda_{H}=\frac{\lambda_{0}}{\sqrt{1-\left(\lambda_{0} / \lambda \mathrm{k}\right)^{2}}}
$$

( $\lambda_{0}$ is the free space wave length)

For $\mathrm{H}_{011}$ resonance $\lambda_{\mathrm{H}}=2 \ell$, one has

$$
2 l=\frac{\lambda_{0}}{\sqrt{1-\left(\lambda_{0} / \lambda k\right)^{2}}}
$$

and thus: $\ell=\mathrm{d}=1.318 \lambda_{0}=4.22$ centimeters for $\lambda_{0}=3.2$ centimeters. Depth of penetration into the metal is very small because of the skineffect. For silver it is given by:

$$
s=6.4 \frac{1}{\sqrt{\text { feps }}}
$$

resulting in 0.66 microns for $f=9400 \mathrm{MC}$.

If the circuits are not loaded the value of $Q$ is found to be 30,900 for this case from:

$$
Q=0.61 \frac{\lambda_{0}}{s}\left[\frac{1+0.17(\mathrm{~d} / \ell)^{2}}{\left[1+0.17(\mathrm{~d} / \mathrm{l})^{3}\right.}\right] 3 / 2
$$

In practice, values between about 15,000 and 20,000 are obtained. The desired high sensitivity requires that the cavity 
dimensions are affected exactly alike by temperature variations. As the measuring cavity is permeated by the medium, and the reference. cavity is sealed, this requirement is difficult to fulfill, and without special precautions one has to take measurement errors into consideration.

The first laboratory model had both cavities mounted into one brass block (see Fig. 4); it was assumed that by good heat conduction adequate heat exchange occurred.

However, tests showed that this arrangement is insufficient to prevent errors. A 10 degree (centigrade) change in the room temperature caused a $25 \mathrm{kc} / \mathrm{s}$ difference of the resonance frequencies; this was caused principally by non-uniform expansion of the cavities. This frequency difference simulated a $2.7 \mathrm{~N}$-unit variation in the refractive index. Therefore, further development included the use of Invar in the fabrication of the resonators; steel end plates will approximately compensate for the small thermal expansion of Invar.

\section{Control Devices}

The klystron repeller voltage has to be adjusted so that a maximum amount of power is delivered. In the vicinity of this maximum the modulation frequency varies approximately as a linear function of time by use of a saw-tooth shaped repeller voltage.

Out of the various regions of the klystron oscillations that one has to be chosen which delivers the greatest amount of power for the smallest change in frequency per volt of repeller voltage (Mc/V). The resonant frequencies of the cavities should be within the immediate vicinity of this maximum.

Such an adjustment is made possible by observing that portion of the wave which is decoupled and reflected by the directional coupler 


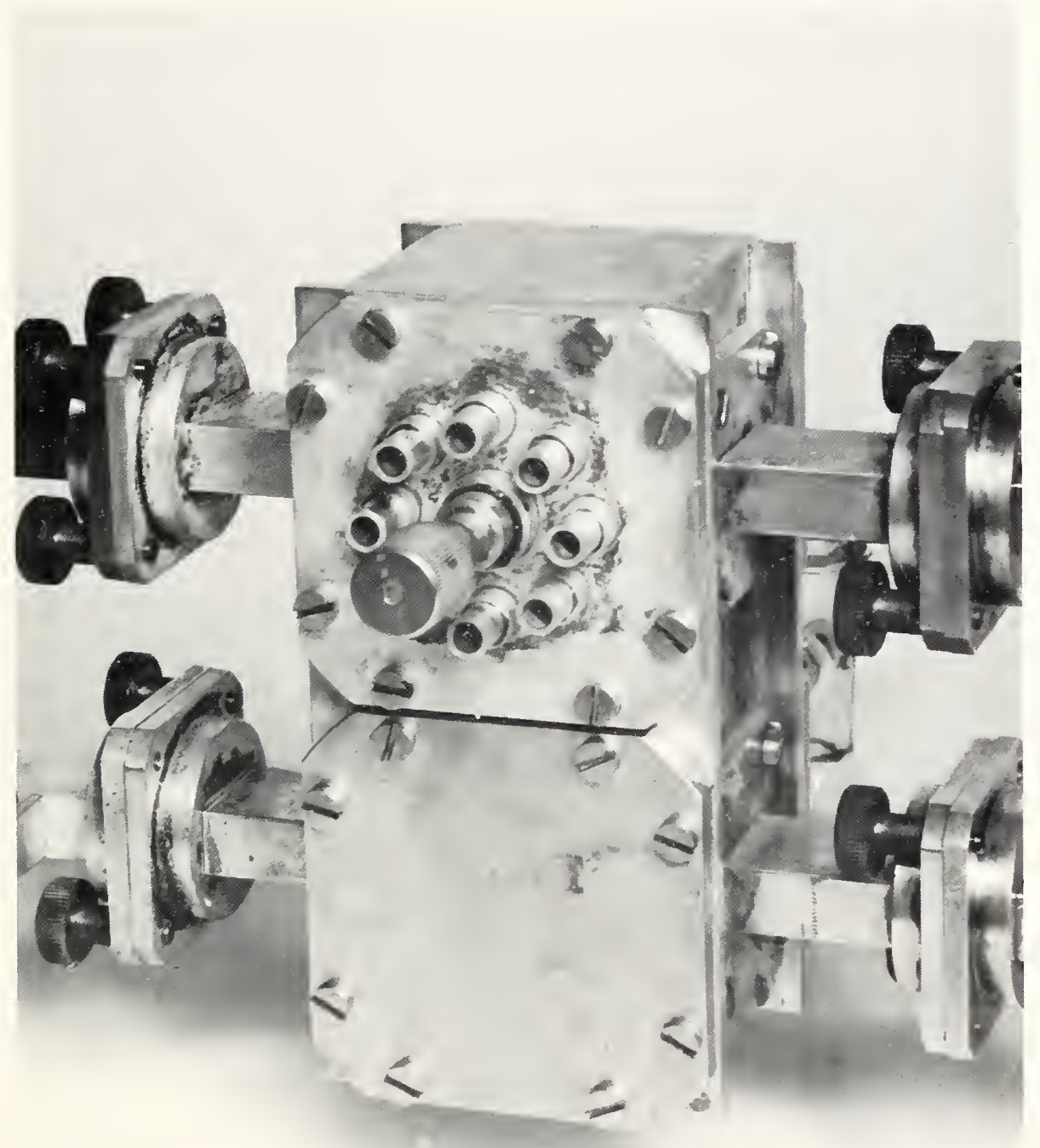

First Version of the Mounted Cavity Resonator Figure 4 

in front of the reference cavity; this portion is recorded by an oscillograph after detection and amplification. This also furnishes continuous control of the operation. Necessary calibrations may be easily accomplished by a wave meter situated between the klystron and the branching- $T$.

\section{Calibration}

The measuring range is first extended by a factor of 10 with reference to the most sensitive adjustment by use of the stepped voltage divider of the saw-tooth generator. The wave meter causes a small saddle in the klystron curve as it draws some power; this is recorded on the control oscillograph. One places the saddle at the beginning and at the end of the curve and reads the corresponding frequency shift on the wave meter. As the potentiometer adjustment is reproducible, one also knows the frequency shift for the most sensitive range of the device. For this position it is now investigated what change in the cavity resonant frequency corresponds to this frequency shift. This is done at the resonator by a small tuning piston with micrometer graduation. As the cavity draws power at resonance, another saddle appears on the control curve. If one now changes the resonant frequency by the tuning piston, the oscillograph saddle shifts, together with the working point on the saw-tooth characteristics. The change in the refiected pulse which appears as well, is not noticeable because of the short return-time of the saw-tooth wave; these pulses may be used as marker points for the beginning and the end of a saw-tooth. If now the resonance saddle is adjusted to these points successively, the deflection of the recorder at the output furnishes the desired sensitivity value in milliamps per megacycle.

At the most sensitive adjustment $50 \mathrm{kc} / \mathrm{s}$ was measured for full deflection of a $1 \mathrm{~mA}$ recorder. From the relation:

$$
\Delta f / f_{0}=\Delta n
$$


one therefore calculates $\Delta \mathrm{n}=8 \times 10^{-8}=0.08 \mathrm{~N}$-units for 1 millimeter deflection.

The calibration was checked by filling the test cavity with a pure gas having a known dielectric constant at various pressures.

\section{Stabilization and Stability of the Device}

In order to obtain consistent readings, the electrical stability of the apparatus has to be especially considered. The power supplies are regulated electronically; the klystron and the other circuits have separate power supplies. Uncontrolled variations in the working point of the saw-tooth characteristics may simulate refractive index variations. Such errors are prevented by automatic readjustment of the repeller voltage. Pulses from the return of the saw-tooth and spikes from the reference cavity regulate another multivibrator; this produces an irregular square wave which effects the readjustment.

In considering instability of the device, long-term and shortterm variations have to be distinguished. If operating conditions are sufficiently stable, long-term variations may be traced to different effects of meteorological parameters on the cavity dimensions. Here humidity has no influence, and pressure effects may be eliminated by rigid construction. The only remaining source of error is thermal expansion as an effect of temperature variation. The use of Invar will permit a reduction of the variations to the necessary low level.

Short-term variations are caused by the electrical instability of the apparatus. Fig. 5 shows recordings taken with closed cavities at maximum sensitivity. The first recording, a portion of which is shown in the upper drawing, was taken using a one-second time constant. The trace was completely smooth over several hours time. For a recording with a 30 millisecond time constant (lower drawing) the 


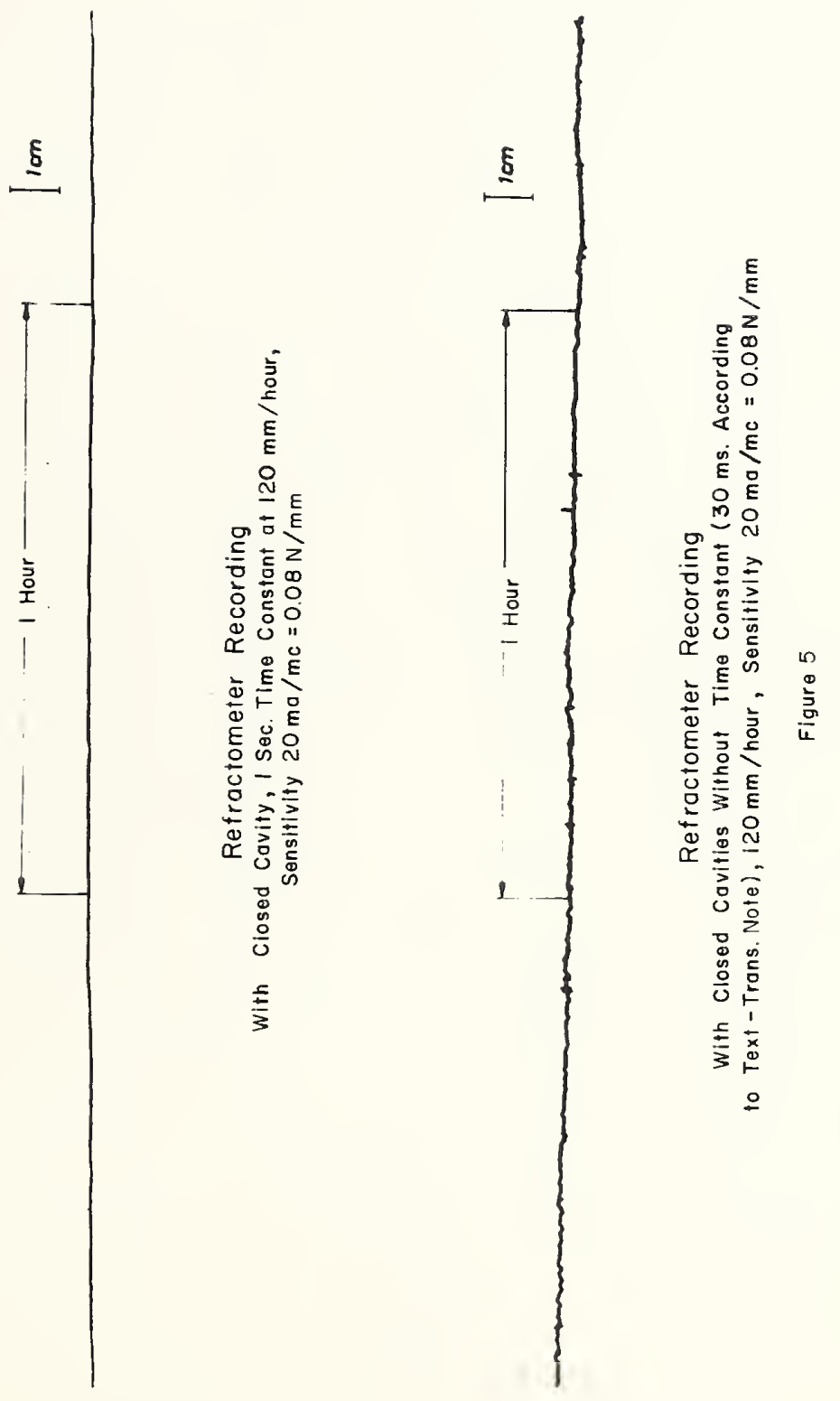



deviations were below one millimeter. In both cases, naturally, inertia and friction of the recording pen contribute (to the time constant).

\section{Measurement Exrors Originating With Air Passage}

The quantities $\Delta T$ and $\Delta e$ of a volume of air which flows through the cavity influence the state of the cavity, but are also affected themselves by the state of the container. The air temperature within the cavity tends toward equalization with the temperature of the walls. In laboratory experiments Birnbaum and Bussey (3) found measurement errors in $\Delta \mathrm{T}$ up to $30 \%$ with a 4.5 meters/second speed of the airflow. This error is reduced to $15 \%$ if the speed is increased to 13 meters/ second. The effect on the value of $\Delta n$, however, was negligible if $\Delta e$ constituted the principal source of variations in $n$.

It was also observed that with Invar cavities a refractive index change of 2 to $3 \mathrm{~N}$-units is simulated if the temperature of one cavity is increased by 1 degree centigrade. The thermal time constant in this case was four minutes for an airstream velocity of 4.5 meters / second. At this velocity 1 degree centigrade was the maximum possible difference between cavity material and air temperature; at 1.3 meters/ second this difference was increased to 2 degrees centigrade.

For steady air velocity and rapid refractive index fluctuations, no measurement error in $\Delta \mathrm{n}$ was found. For usual meteorological conditions Birnbaum observed recording shifts of not more than 0.2 $\mathrm{N}$-units over several minutes time. Our own investigations using steel-compensated Invar are in progress.

No effect was observed on the water vapor content of the medium as a result of water vapor absorption at the walls. However, for condensation with 0.03 millimeter thickness of the water layer variations up to $1 \mathrm{~N}$-unit were measured. 
Construction of the Device

Fig. 6 shows the test rack. The two lower chass is contain power supplies; above them is the phase meter and on top is the control pane1. The reference cavity is mounted directly on the front panel of the phase meter; it may be tuned by means of the graduated knob of the micrometer located on its base. The connection to the wave guide leading to the measuring cavity is located on the left side of the rack.

Figs. 7 and 8 show the construction of the cavity resonators. The reference cavity has the tuning piston attached to metal bellows which keep the cavity air-tight; the piston penetrates the cavity through the bottom plate. A compression spring is used to compensate for the exterior air pressure and thus, tuning is facilitated.

In order to improve the passage of the airstream through the measuring cavity in case larger openings are used, the diameter of the steel end plates is reduced as much as permissible for the required Q.

\section{Initial Test Result}

Initial recordings were performed on the roof of the institute building. The direct effect of the sun on the cavity was prevented by a large sheet metal cover which was open in the direction of air passage. A small fan provided a steady air stream.

The record shown on Fig. 9 was obtained on January 10, 1958, with partially clear and partially cloudy sky. It is seen that clouds passing in front of the sun are noticeable at once by a change in the refractivity of the order of magnitude $1 \times 10^{-6}$, or $1 \mathrm{~N}$-unit. The small fluctuations which are always apparent amount to about $2 \times 10^{-7}$ to 


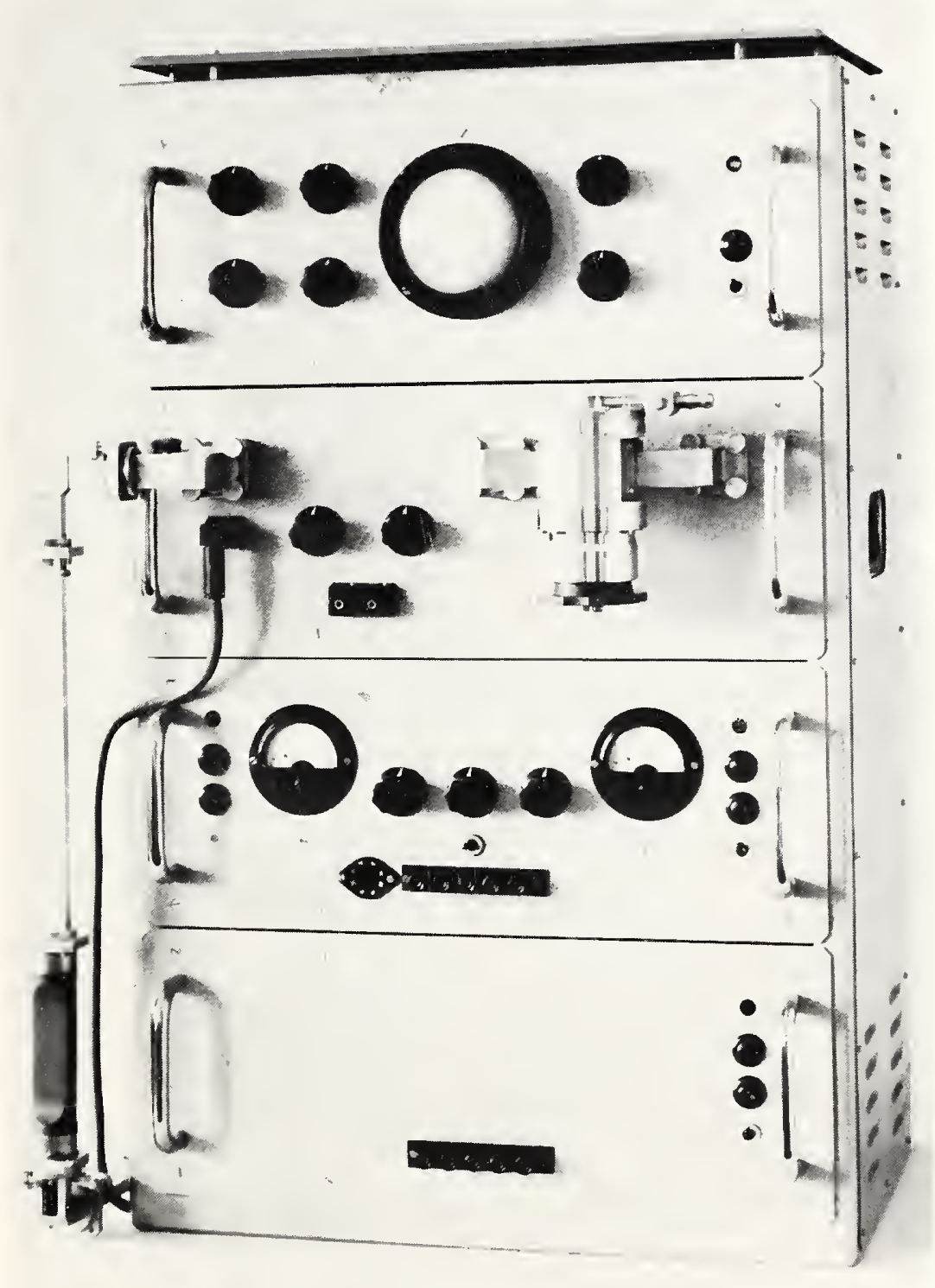

Test Rack

Figure 6 



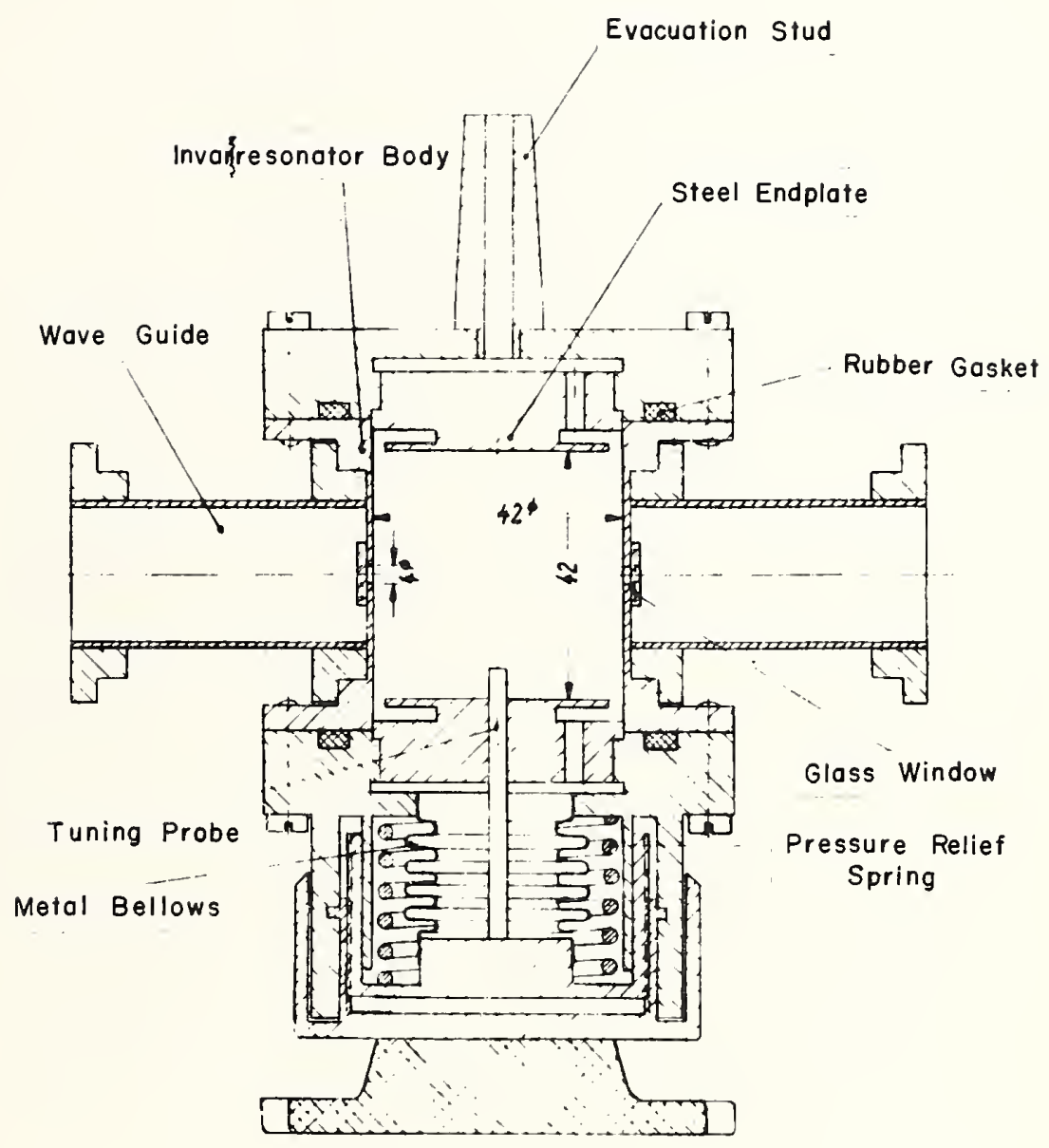

Reference Cavity

Figure 7 



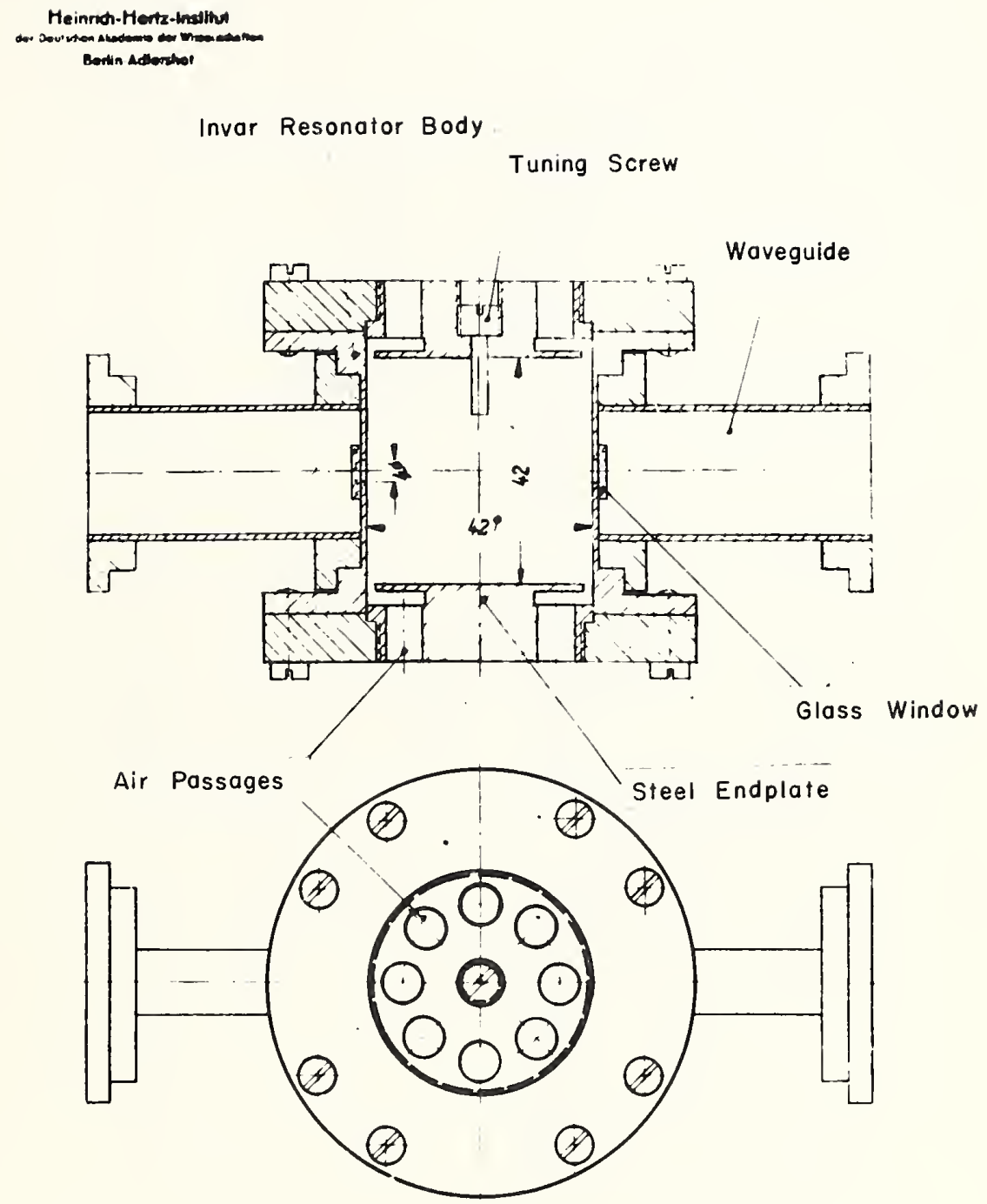

Measuring Cavity

Figure 8 



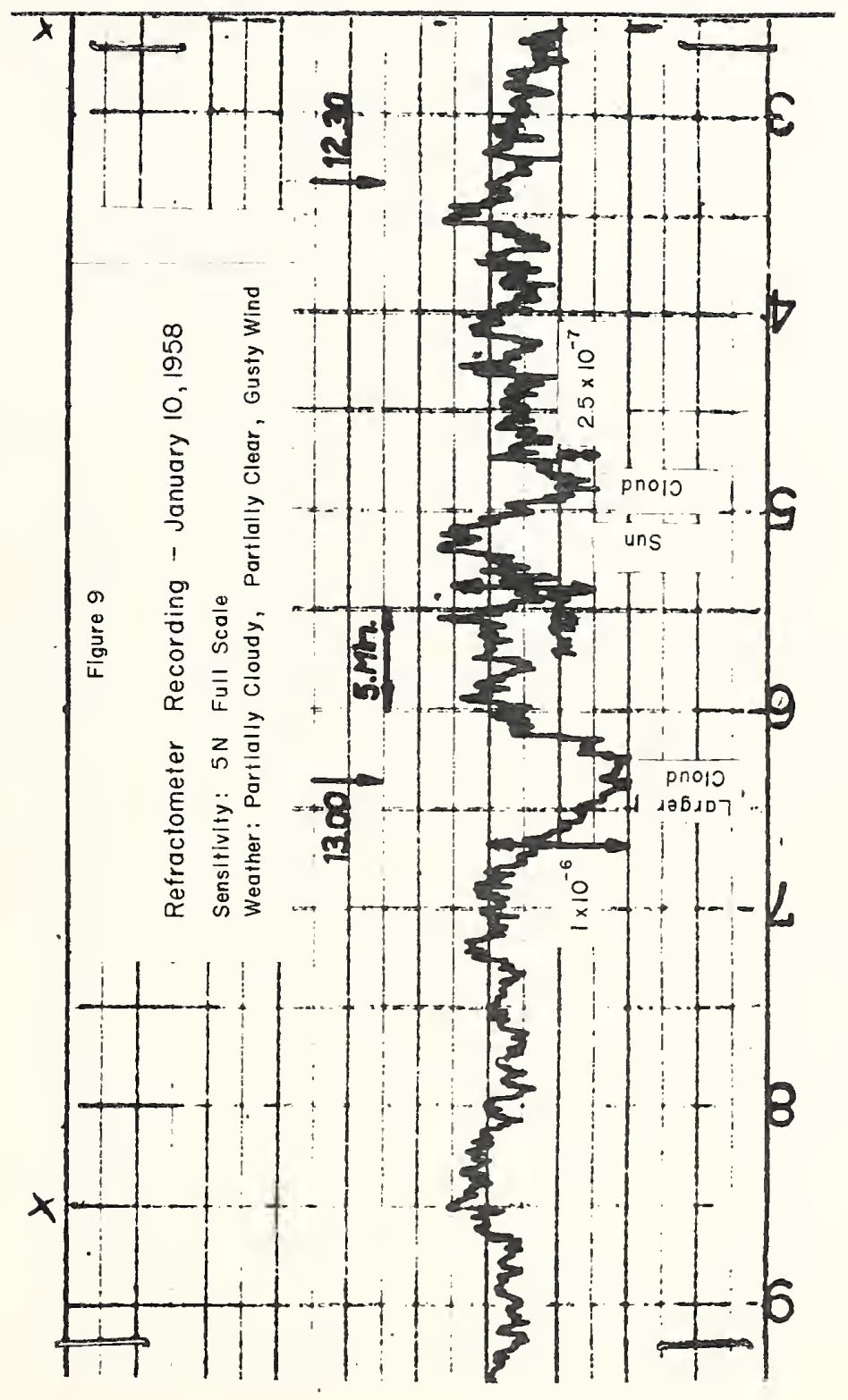



$3 \times 10^{-7}$, or 0.2 to $0.3 \mathrm{~N}$-units; a single oscillation lasted for 15 to 20 seconds. For an air stream velocity of 2 to 3 meters per second, the horizontal dimension (of the blob) amounts to 30-60 meters, and the gradient to values from $0.3 \times 10^{-8}$ per meter to $1 \times 10^{-8}$ per meter. The effect of rain is shown on Fig. 10 for the same recording day. After a relatively smooth behavior the beginning rain produced at once larger variations on the order of 0.4 to $0.8 \mathrm{~N}$-units. The time period was approximately the same.

The next recording of February 13, 1958, shows a much more perturbed character (Fig. 11). This day fell within the period of an extreme warm front passage with more than 10 degrees centigrade temperature increase. The small variations here were as large as 1. $4 \mathrm{~N}$-units. Besides that,larger fluctuations were observed extending over 12 to 18 minute periods, and having amplitudes up to $5 \mathrm{~N}$-units. For 2 to 3 meters per second air stream speed, a long dimension of 1.5 to 3 kilometers is obtained. In accordance with experience one may assume that such atmospheric formations have even stronger refractive index variations with height, as the vertical changes in gradient are generally larger than the horizontal ones. In the course of diversity measurement over a 360 kilometer path, we have frequently encountered scattering formations which had comparable dimensions and were moving with the wind at wind velocities.

A very substantial change amounting to $6 \mathrm{~N}$-units over a period of 45 minutes was noticed somewhat later on the same day (see Fig. 12). Although the mean gradient was only $1 \times 10^{-9}$ per meter, individual small variations reached $2 \mathrm{~N}$-units with a gradient between 3 and $7 \times 10^{-8}$ per meter.

Recordings for the previous day were relatively uniform, as seen by Fig. 13. However, even then the rapid fluctuations showed 
amplitudes up to $1 \mathrm{~N}$-unit.

The unstable behavior of the refractive index was observed yet on February 14, 1958, Fig. 14 shows one of the fluctuations with 3.6 $\mathrm{N}$-units amplitude observed on that day.

During those days we also observed a marked increase in received signal strength over a test path using transmissions at a wave length of 10 centimeters. Besides that, deviations of the field strength behavior as a function of the antenna azimuth were noted which were different from the usual values recorded over longer periods of time.

Currently test series are being conducted near the ground, at various levels on a 80-meter tower, and also in an aircraft. 


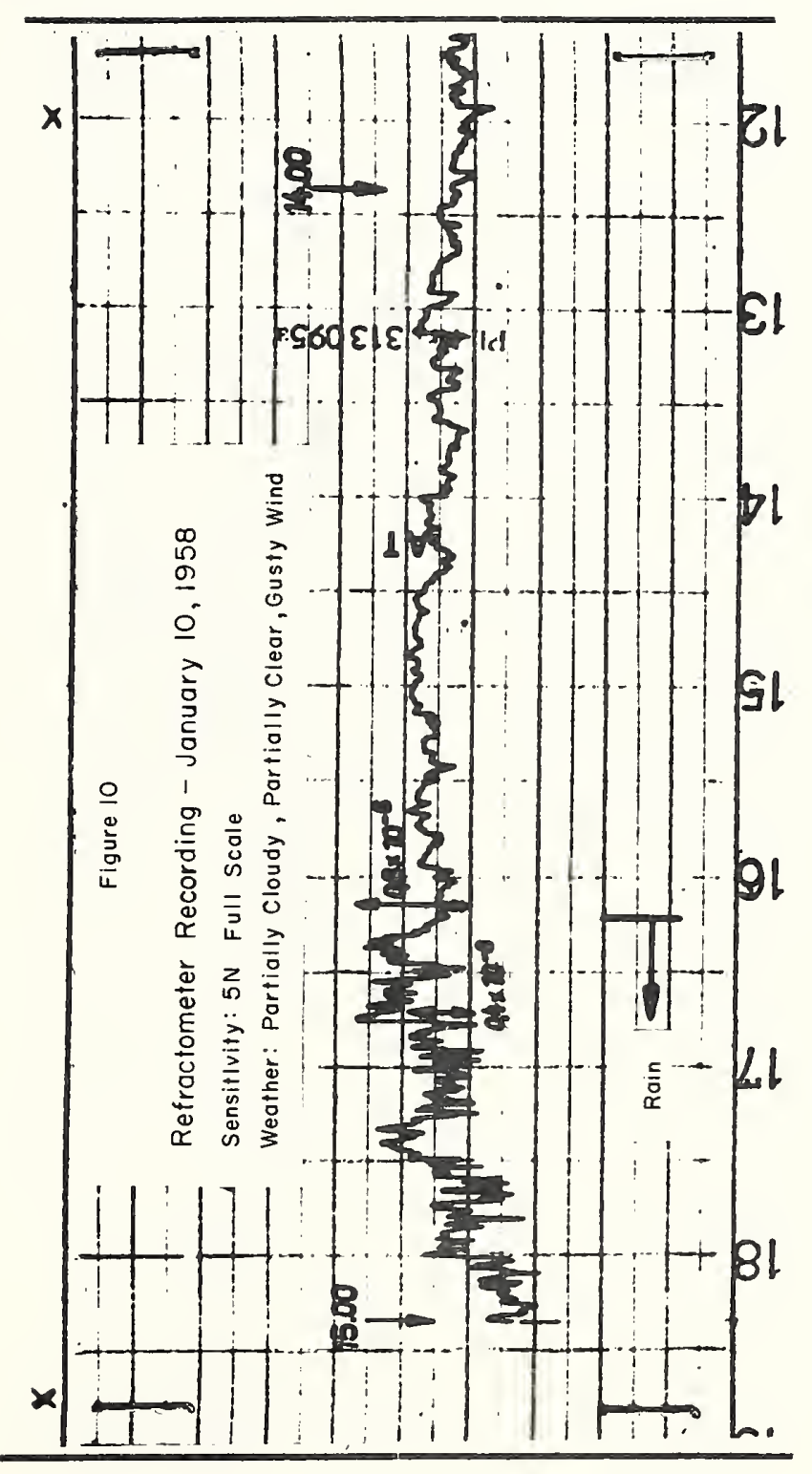





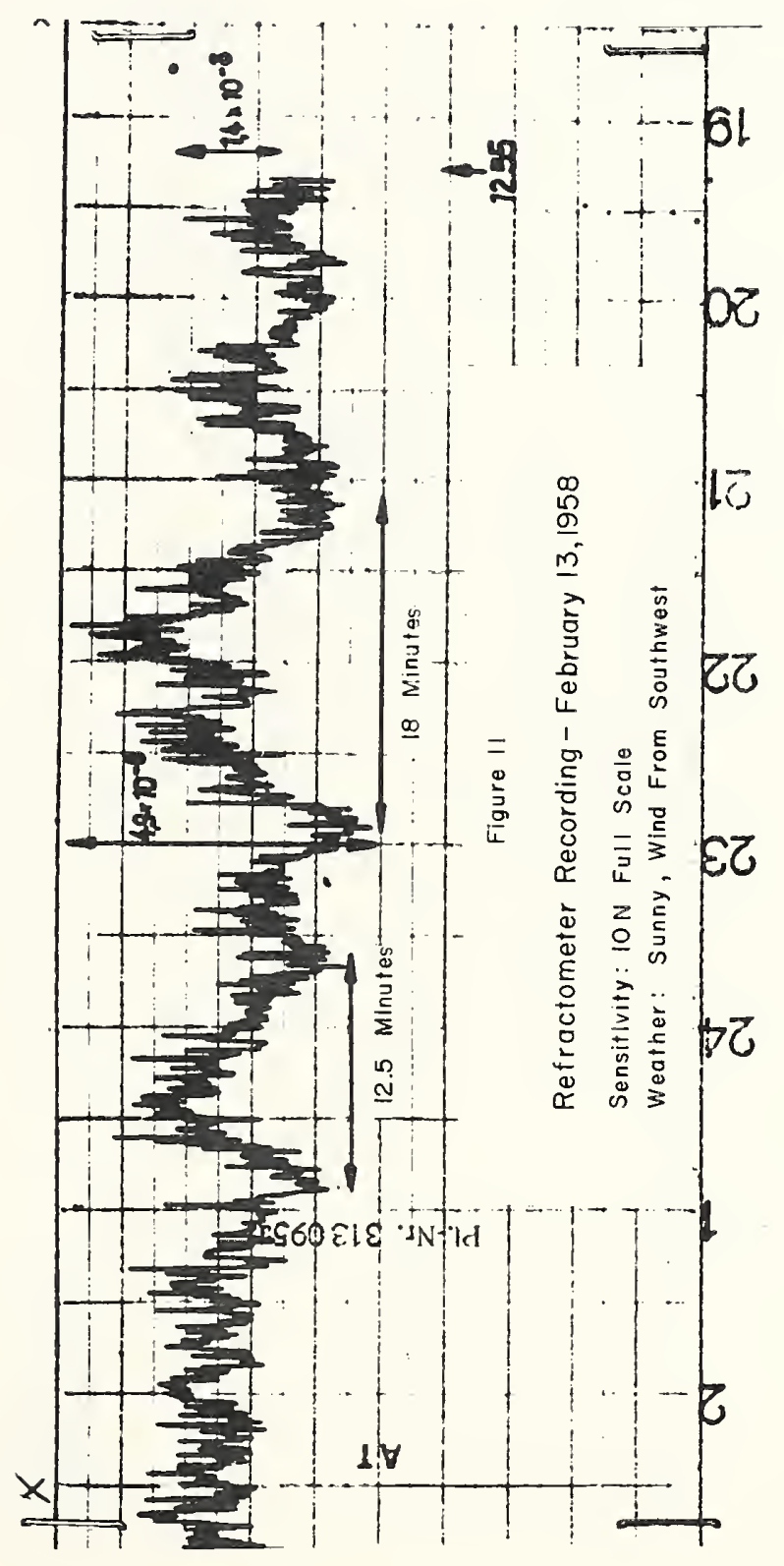





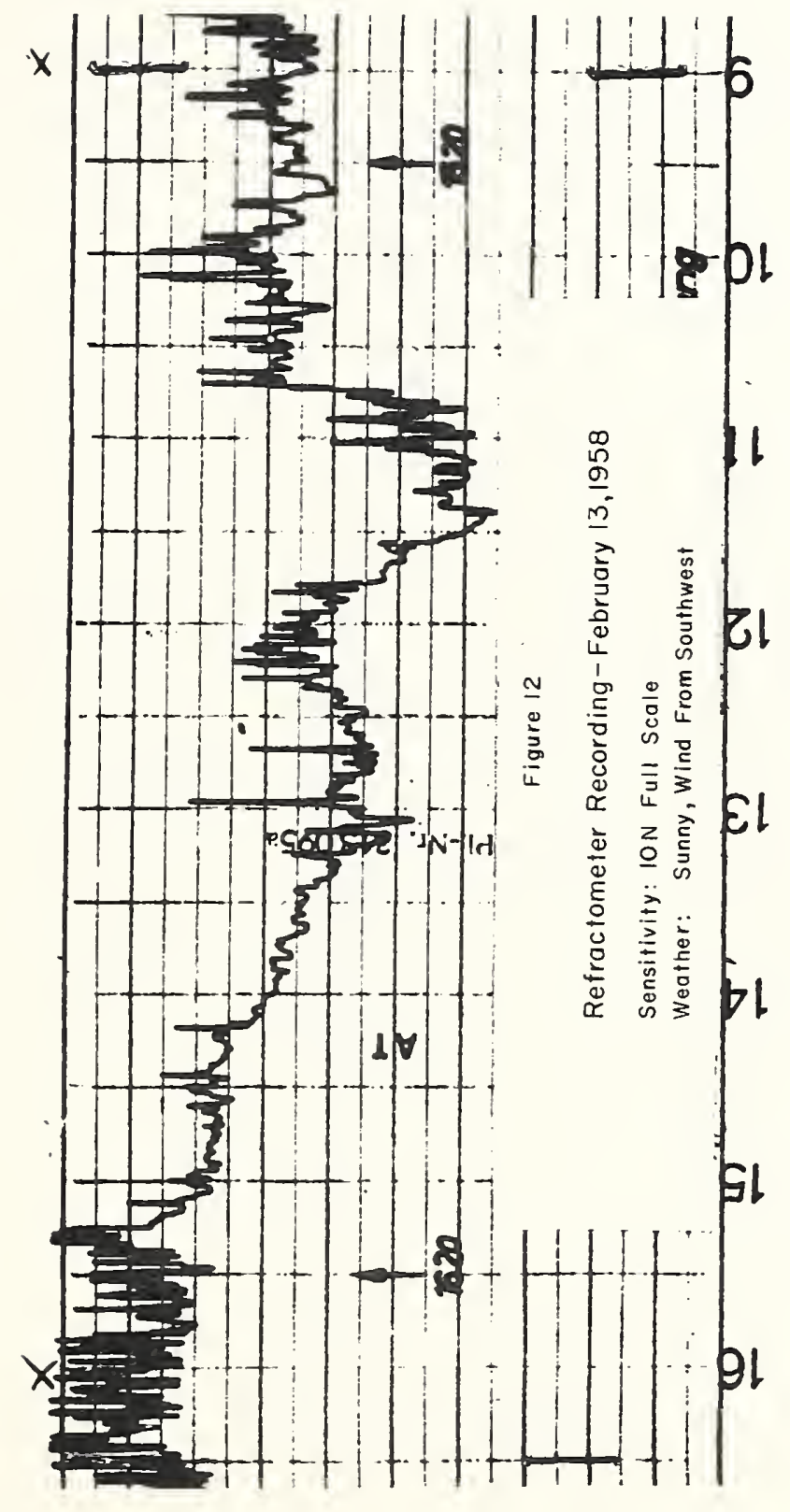





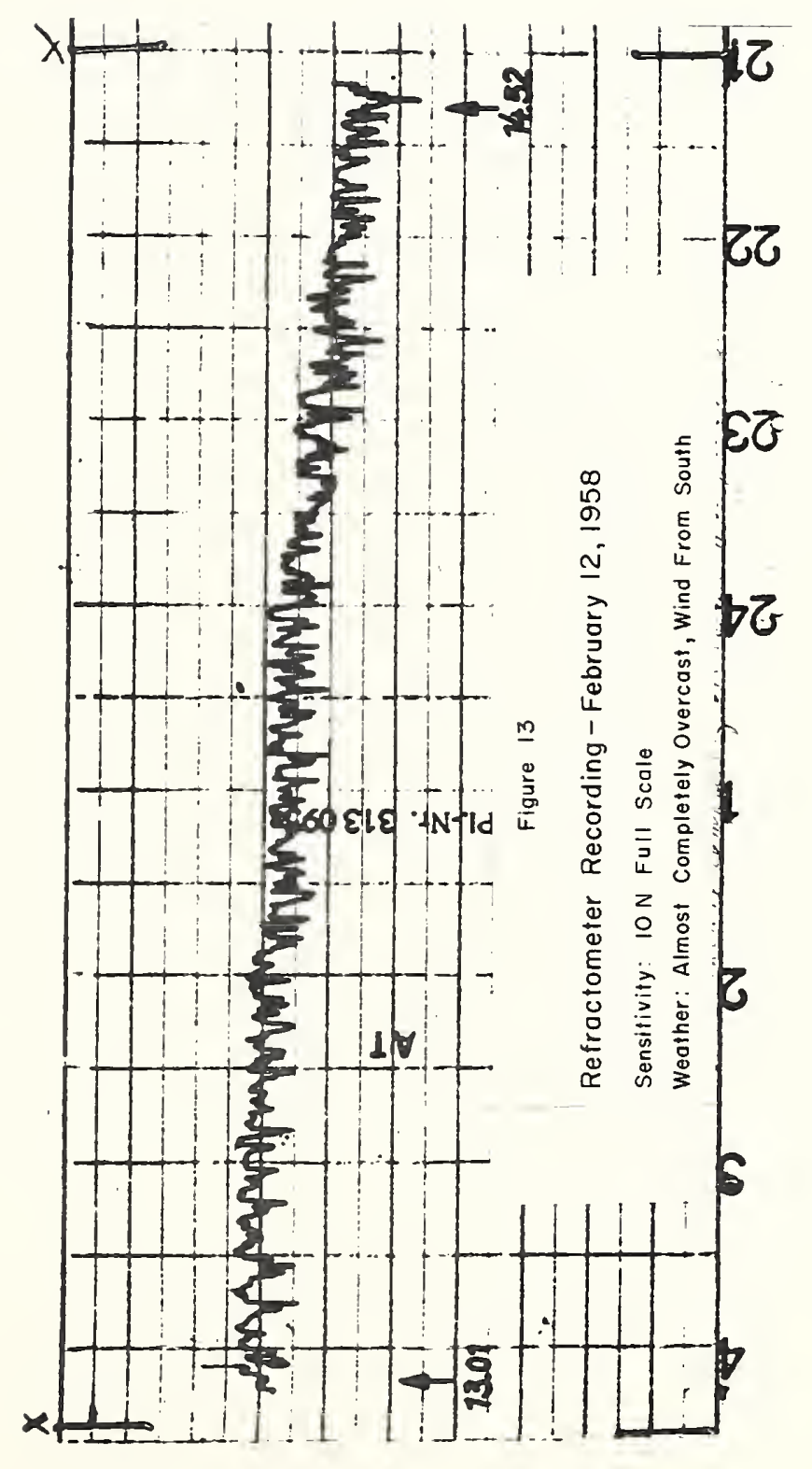





\section{REFERENCES}

1. C. M. Crain, "Measurements of the Parameters Involved in the Theory of Radio Scattering in the Troposphere ", Proc. IRE, p. 50, January 1952.

2. C. M. Crain, "Survey of Airborne Microwave Refractometer Measurements ", Proc. IRE, p. 1405, October 1955.

3. G. Birnbaum and H. E. Bussey, "Amplitude, Scale and Spectrum of Refractive Index Inhomogeneities in the First 125 Meters of the Atmosphere ", Proc. IRE, p. 1412, October 1955.

4. C. M. Crain, "Microwave Refractometer Predicts Propagation ", Electronics, p. 150, December 1956.

5. M. C. Thompson, Jr. and M. J. Vetter, "A Microwave Refractometer for Use in Small Aircraft ", NBS Report 5057, April 10, 1957. 



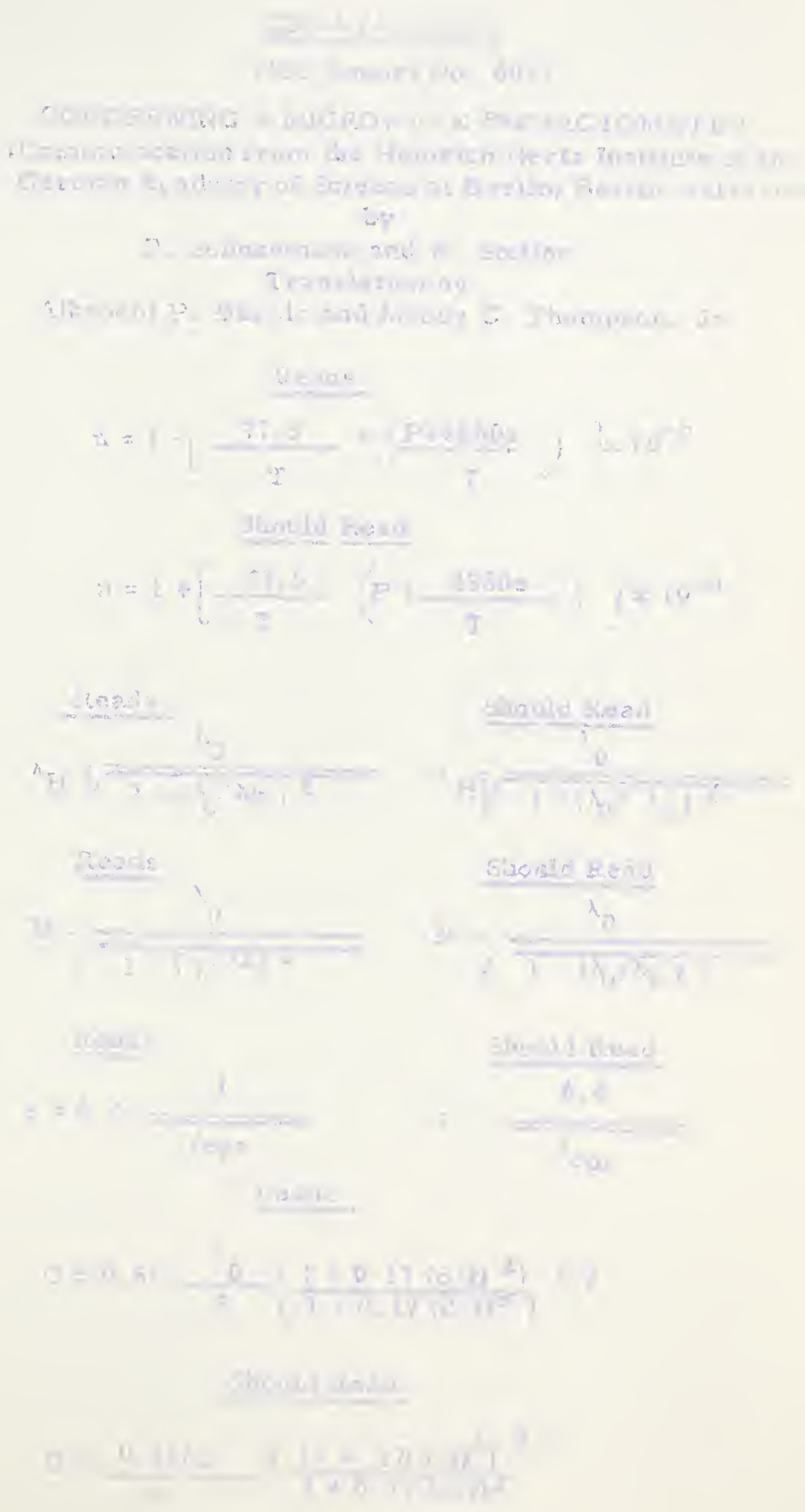



U. S. DEPARTMENT OF COMMERCE

Sinclair Weeks, Secretary

NATIONAL BUREAU OF STANDARDS

A. V. Astin, Director

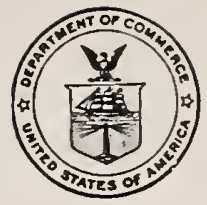

\section{THE NATIONAL BUREAU OF STANDARDS}

The scope of the scientific program of the National Bureau of Standards at laboratory centers in Washington, D. C., and Boulder, Colorado, is given in the following outline:

Washington, D.C.

Electricity and Electronics. Resistance and Reactance. Electron Devices. Electrical Instruments. Magnetic Measurements. Dielectrics. Engineering Electronics. Electronic Instrumentation. Electrochemistry.

Optics and Metrology. Photometry and Colorimetry. Optical Instruments. Photographic Technology. Length. Engineering Metrology.

Heat. Temperature Physics. Thermodynamics. Cryogenic Physics. Rheology. Engine Fuels. Free Radicals.

Atomic and Radiation Physics. Spectroscopy. Radiometry. Mass Spectrometry. Solid State Physics. Electron Physics. Atomic Physics. Neutron Physics. Nuclear Physics. Radioactivity. X-rays. Betatron. Nucleonic Instrumentation. Radiological Equipment. AEC Radiation Instruments.

Chemistry. Organic Coatings. Surface Chemistry. Organic Chemistry. Analytical Chemistry. Inorganic Chemistry. Electrodeposition. Molecular Structure and Properties. Physical Chemistry. Thermochemistry. Spectrochemistry. Pure Substances.

Mechanics. Sound. Mechanical Instruments. Fluid Mechanics. Engineering Mechanics. Mass and Scale. Capacity, Density, and Fluid Meters. Combustion Controls.

Organic and Fibrous Materials. Rubber. Textiles. Paper. Leather. Testing and Specifications. Polymer Structure. Plastics. Dental Research.

Metallurgy. Thermal Metallurgy. Chemical Metallurgy. Mechanical Metallurgy. Corrosion. Metal Physics.

Mineral Products. Engineering Ceramics. Glass. Refractories. Enameled Metals. Concreting Materials. Constitution and Microstructure.

Building Technology. Structural Engineering. Fire Protection. Air Conditioning, Heating, and Refrigeration. Floor, Roof, and Wall Coverings. Codes and Safety Standards. Heat Transfer. Applied Mathematics. Numerical Analysis. Computation. Statistical Engineering. Mathematical Physics.

Data Processing Systems. SEAC Engineering Group. Components and Techniques. Digital Circuitry. Digital Systems. Analogue Systems. Application Engineering.

- Office of Basic Instrumentation

$$
\begin{aligned}
& \text { Boulder, Colorado } \\
& \text { BOULDER LABORATORIES } \\
& \text { F. W. Brown, Director }
\end{aligned}
$$

- Office of Weights and Measures

Cryogenic Engineering. Cryogenic Equipment. Cryogenic Processes. Properties of Materials. Gas Liquefaction.

Radio Propagation Physics. Upper Atmosphere Research. Ionosphere Research. Regular Propagation Services. Sun-Earth Relationships. VHF Research. Ionospheric Communications Systems.

Radio Propagation Engineering. Data Reduction Instrumentation. Modulation Systems. Navigation Systems. Radio Noise. Tropospheric Measurements. Tropospheric Analysis. Radio Systems Application Engineering.

Radio Standards. High Frequency Electrical Standards. Radio Broadcast Service. High Frequency Impedance Standards. Electronic Calibration Center. Microwave Physics. Microwave Circuit Standards. 


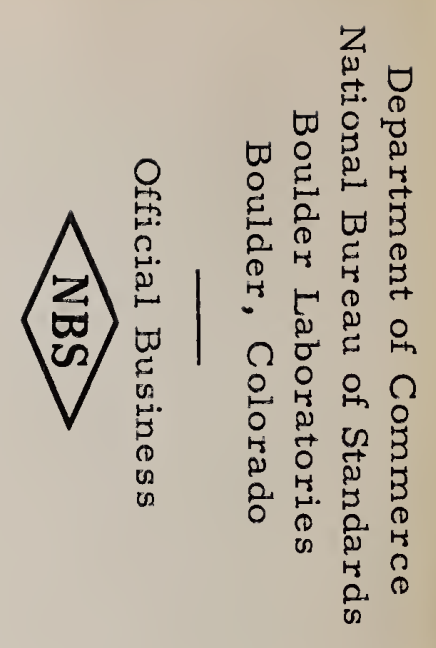

